\title{
ARQUIVOLOGIA, CIÊNCIA DA INFORMAÇÃO E AS DUAS FACES DE JANO
}

\author{
Archival Science, Information Science and the two face of Janus
}

\author{
Johanna W. Smit \\ Universidade de São Paulo, cbdjoke@usp.br
}

\begin{abstract}
Resumo
Propor soluções práticas para responder ao leque de questões relacionadas ao acesso à informação resume o objetivo da Ciência da Informação, que se desdobra em diferentes contextos de aplicação prática identificados como arquivos, bibliotecas e museus. A distinção entre estes diferentes espaços de informação não reside na diferença dos documentos custodiados, mas na função a eles atribuída, produto de histórias e construções teóricas diferentes. À distinção na função atribuída aos documentos correspondem diferenças nos métodos de trabalho, enfatizando-se a importância da identificação do contexto de produção do documento arquivístico. Apesar de funções diferentes atribuídas aos documentos de arquivo, biblioteca e museu, organizar o acesso à informação constitui o objetivo comum, que visa à construção de pontes entre o passado e o futuro, a exemplo de Jano, o deus da mitologia romana, que tem duas faces, uma olhando para o passado e a outra para o futuro.
\end{abstract}

Palavras-Chave: Arquivologia; Ciência da Informação; Acesso; Aplicações práticas; Contexto de Produção

\section{A Ciência da Informação e as 3 Marias}

Dispensando o retorno a uma vasta bibliografia produzida nos últimos 50 ou 60 anos que trata das diferentes definições que podem ser dadas ao termo "Ciência da Informação", limito-me a caracterizá-la como uma ciência pós-moderna, o que significa que ela não se caracteriza por tratar um objeto único (não compartilhado com nenhuma outra ciência) e recorre a métodos próprios, mas por tratar um leque de questões geradas pelas ciências modernas e pela sociedade contemporânea, para as quais propõe soluções práticas. O leque de questões envolvidas no acesso à informação configura o objetivo da área.

Ciente de que a afirmação a seguir não é consensual, postulo aqui que a denominação "Ciência da Informação" (doravante resumida pela sigla CI), investida do objetivo acima resumido, representa uma área do conhecimento que, ao propor soluções práticas, se desdobra em diferentes contextos de aplicação institucionais e profissionais. Refiro-me à diferença entre arquivos, bibliotecas, museus e outros tipos de espaços de informação e memória (acervos e serviços) que, na ausência de inspiração melhor, resumi pelo codinome "3 Mari-

\begin{abstract}
The proposition of practical solutions for the array of questions related to information access summarizes the objective of Information Science, which unfolds in different contexts of practical applications identified as archives, libraries and museums. The distinction between the different informational spaces does not rely on the difference between documents kept in custody but on the function assigned to them, fruit of different histories and theoretical constructions. This difference in the attributed function of documents corresponds to different working methods: the importance of the identification of the context of creation of the archival document is emphasized. In spite of the different functions assigned to archival, library and museum documents, the organization of access to information remains a common objective, aiming at the construction of bridges between the past and the future, following the example of the roman mythological god Janus, who has two faces: one looking to the past and the other to the future.
\end{abstract}

Keywords: Archival Science; Information Science; Access; Practical Applications; Context of Creation.

as" alguns anos atrás (Smit, 1993). Do que consistem em estes "contextos institucionais de aplicação"?

A distinção entre os diferentes "contextos", baseada nos tipos de documentos custodiados, foi ultrapassada há tempos e teve sua sentença de morte decretada com o advento do documento digital, presente em todos os espaços de forma cada vez mais incontornável. Se o tipo de documento custodiado não fornece mais o traço distintivo, e retomando o ideário de Otlet (1934), que anteviu o caráter aplicado e operacional da área (p.373), resta-nos adotar uma visão funcionalista, ou seja, enfatizar a função atribuída aos documentos enquanto traço que distingue os diferentes "contextos". Assim como o mesmo objeto pode pertencer a acervos museológicos muito diferentes - uma faca de prata pode compor o acervo do museu do crime, ou do museu de gastronomia ou ainda do museu de ourivesaria o mesmo documento pode estar presente em arquivos, bibliotecas e museus (pense-se na transversalidade da iconografia e das fotografias, sistematicamente presentes nos diferentes espaços) mas não será descrito e organizado do mesmo modo. Este ponto será detalhado a seguir. 


\section{Documento e/ou informação}

Assim como a distinção dos "contextos" em função dos tipos de documentos custodiados não nos ajuda, levando-nos a optar pela distinção por funções atribuídas aos documentos, trabalhar com a noção de documento no sentido do senso comum tampouco nos avança. Um dos entraves para consolidarmos a área da Ciência da Informação reside exatamente no fato de ainda não dispormos de uma linguagem de especialidade própria. Recorremos ao termo "documento" tal como entendido no senso comum, sendo necessário atribuir-lhe uma camada de especificidade, de modo a inserir o termo nas preocupações da área da CI.

Um impressionante histórico do documento através dos séculos nos é proposto por Lund (2009), caracterizado inicialmente como objeto escrito, ao qual foi acrescentada uma função jurídica - matéria de prova - para em seguida enfatizar no documento a noção de informação (p.400). Outros tantos trataram do tema, variando de uma concepção ilimitada, sem fronteiras e, portanto, inviável, proposta por Otlet (1934), a concepções excessivamente restritivas, que associam o termo a um registro sobre suporte papel (Jesse Shera, por exemplo, citado por Buckland, 1997, p.807). Esta concepção restritiva fez com que por muito tempo os objetos museológicos não fossem considerados em sua condição de documentos, do que decorria a conclusão segundo a qual a museologia não faria parte da grande família da CI.

Reforçando a abordagem funcionalista, o conceito de evidência, proposto por Suzanne Briet nos idos de 1951 em um modesto folheto de 48 páginas, será aqui adotado por ser considerado fundamental. Resumindo, segundo Briet, o objeto da CI (ela se referia à documentação, aqui considerada precursora da $\mathrm{CI}$ ) é constituído de objetos intencionalmente considerados evidências de algo. De forma lapidar, Briet distingue uma estrela no céu da fotografia da mesma estrela, a pedra no rio da pedra incorporada ao acervo do museu e um animal na natureza do animal no zoológico. Os exemplos enfatizam a intencionalidade que distingue a natureza (céu, rio ou natureza tout court) de objetos presentes em acervos (fotográficos, museológicos, zoológicos, de acordo com os exemplos fornecidos por "Madame Documentation", como Briet foi chamada por Michael Buckland). A partir das colocações de Briet podem ser destacadas quatro conclusões basilares:

1. O "documento" é considerado "documento" porque considerado evidência de algo: um fato, um objeto, um acontecimento, uma pessoa, etc.

2. Considerar que algo é uma evidência equivale a reconhecer que tratamos de objetos com um valor atribuído. Este valor é considerado uma "informação". A "informação" não é um dado livremente encontrado na natureza, mas um valor atribuído a algo. E se o valor é atribuído, torna-se imediatamente forçoso reconhecer que o mesmo "algo" pode ter - ou não ter um valor atribuído, e que o valor atribuído pode variar muito, de acordo com as pessoas, as culturas, o tempo e o espaço - dimensões das quais nada escapa! Buckland (1991, p.356-357) introduz duas condições interessantes ao afirmar que a informação, para ser entendida, deve ser contextualizada pois determinada situacional e consensualmente. Recorro a um texto anterior, quando disse:

"A noção de que a informação adquire (pode adquirir) sentido de acordo com o contexto aponta para uma dicotomia que gera discussões muito ricas ao propor a distinção entre informação como objeto a ser organizado e disseminado e o fenômeno informacional, dinâmico e segundo o qual o contexto é determinante para que a informação passe a fazer sentido" (Smit, 2011, p.34).

A introdução da noção de contexto na compreensão da informação voltará à discussão na seção 4 .

3. Para que a evidência possa ser acessada em outros tempos e espaços sua identificação ou registro são pressupostos. Decorre deste ponto a distinção entre informação e documento: a informação é atribuída a "algo", intencionalmente conservado, quer intencionalmente registrado (texto, gravura, fotografia, vídeo, etc.) ou intencionalmente institucionalizado (pedra, animal, objeto museológico, portanto). A noção de "documento" incorpora assim tanto os registros intencionais quanto os objetos intencionalmente institucionalizados. Nesta acepção, arquivos, bibliotecas e museus custodiam "documentos".

4. Ainda de acordo com Buckland (1991, p.353) o termo "evidência" é apropriado porque implica passividade, exatamente como o termo "informação": a informação não "faz nada", o ser humano faz algo com ela acreditando, no melhor dos mundos, no poder transformador do conhecimento gerado a partir do acesso à informação.

\section{As diferentes lógicas aplicadas à informação e aos documentos}

$\mathrm{O}$ reconhecimento da relatividade do "objeto" da CI, acima identificado como "documento", que pressupõe atribuição de valor por alguém (uma cultura, uma sociedade, uma instituição, frequentemente entidades coletivas mas em alguns casos posicionamentos exclusivamente individuais) torna fácil entender a diferença entre suas várias áreas de aplicação - áreas profissionais, reconhecidas socialmente na condição de distintas embora irmãs: volto portanto à diferença entre arquivos, bibliotecas e museus. Todas reúnem algo considerado documento (atribuição de valor), e esta reunião visa sempre ao pressuposto de sua utilidade futura, quer esta utilidade seja muito evidente ou simplesmente suposta. Uma utilidade muito evidente caracteriza uma boa parte do discurso arquivístico, a respeito da necessidade de 
preservar e organizar documentos produzidos para viabilizar ações, comprovar a realização ou o abandono das referidas ações e preservar a memória das ações. Em outro ambiente, soa estranho falar acerca da utilidade de um livro de poesia ou uma obra de arte, mas explicita ou implicitamente a questão foi colocada, que seja tendo em vista aspectos financeiros relacionados à aquisição e preservação dos referidos objetos. Tabelas de temporalidade de documentos, políticas de seleção, curadoria de conteúdo e de coleções são as instâncias que executam a seleção, ou seja, a atribuição de valor.

A seleção assim concebida obviamente pode ser realizada de acordo com uma infinidade de critérios considerados socialmente aceitáveis e adequados (as dimensões do tempo e do espaço não perdem nunca seu protagonismo!). A seleção opera em dois momentos, sendo que o primeiro determina se o "algo" é arquivístico, biblioteconômico ou museológico. No segundo momento, já inserido no contexto predeterminado pelas instituições arquivísticas, biblioteconômicas ou museológicas, decide-se se "vale a pena" inserir aquele "algo" no ambiente do arquivo, da biblioteca ou do museu. O "documento" é, portanto, selecionado, passando a constituir um documento reconhecido enquanto documento (atribuição de valor) e recebendo uma chancela oficial, um carimbo institucional, muitas vezes até um carimbo físico. A seleção resulta numa institucionalização de algo que foi considerado "documento".

O olhar que as diferentes áreas de aplicação prática dos objetivos gerais da CI (3 Marias) lançam sobre os documentos são diferentes, produtos de construções teóricas e históricos diferentes de evolução das áreas. $\mathrm{Ou}$ seja:

"A forma/função pela qual o documento é criado é que vai determinar seu uso e destino de armazenamento futuro. É a razão de sua origem e emprego, e não o suporte sobre o qual está constituído, o que vai determinar sua condição de documento de arquivo, de biblioteca, de centro de documentação ou de museu" (Bellotto, 1991, p.14).

A distinção formal entre as áreas assumiu com o tempo ares de um dogma, respaldado por diferentes legislações profissionais e associações científicas, culturais e profissionais - caracterizando um momento de afirmação das diferentes profissões - mas hoje tende a se diluir face à proliferação de espaços de informação, com nomeações muito variadas e a emergência dos documentos digitais, que transitam de forma pouco cerimoniosa entre eles. No entanto, não se pode perder de vista que as visões lançadas sobre os documentos continuam diferentes de acordo com os espaços, e continuarão diferentes pelo simples fato de serem o produto de funções diferentes atribuídas aos documentos e, portanto, funções institucionais diferenciadas. Homulos, em 1990, propôs resumidamente a distinção segundo a qual a biblioteca enfatiza a informação compreendida nos documentos, nos museus os documentos fornecem informações sobre a sociedade que os produziu e os documentos de arquivo fornecem informações sobre a instituição ou pessoa que os acumulou. Outra forma para expressar a diferença é proposta por Camargo e Goulart (2015, p.23) quando as autoras distinguem as funções primárias dos arquivos - administrativas (viabilizar e comprovar atividades de instituições e pessoas) das funções primárias de bibliotecas e museus educacionais, científicas, técnicas e culturais. A função viabilizadora e comprobatória associada aos documentos de arquivo conduz a outra distinção, ainda segundo as autoras: os documentos de arquivo têm um estatuto documental congênito, ao passo que os documentos em bibliotecas e museus têm um estatuto documental atribuído.

O valor atribuído aos documentos - congênito ou por atribuição - não pode ser ignorado, mas tampouco pode obscurecer um fato: as instituições incluídas na família das 3 Marias perseguem os mesmos objetivos, embora com finalidades diferentes (administrativas ou educacionais-culturais), a saber a reunião de documentos visando organizar seu acesso - potencial ou real. Quando olhamos para as 3 Marias de forma menos abstrata, as diferenças aparecem, acarretadas pelas funções diferentes atribuídas aos documentos, desaguando em métodos de trabalho igualmente diferenciados. No entanto, repetindo-me, continuo identificando as diferentes áreas na condição de operadoras - diferentes de um mesmo objetivo comum e maior da CI, qual seja, o acesso à informação (cf. seção 1 acima).

\section{$4 \mathrm{O}$ arquivo e as duas faces de Jano}

Na mitologia romana Jano é um deus associado às trocas (entrada e saída), às colheitas agrícolas e ao tempo. A sua dupla face também simboliza o passado e o futuro, uma face olhando para trás, a outra para a frente. Segundo a mitologia, passado e futuro não se opõem, mas se complementam ao se reunirem no mesmo deus. A preservação de acervos ou sua representação institucionaliza documentos produzidos no passado (recentíssimo, no caso de arquivos correntes ou distante no caso dos arquivos permanentes) permitindo projetar o futuro, fundamentar decisões, prever variáveis, etc.

A afirmação segundo a qual o arquivo é essencial para a tomada de decisões deve ser entendida, hoje, de uma forma menos literal. A sociedade contemporânea, globalizada, bombardeada por um excesso de informações (nem sempre verdadeiras), submetida a constantes críticas através das redes sociais (nem sempre fundamentadas) e cobrada em termos de transparência, vive uma mutação permanente em função de uma dinâmica em boa parte impulsionada ou produzida pela tecnologia. As instituições, empresas e corporações são submetidas à mesma dinâmica e frequentemente a tomada de decisões acontece diante de cenários novos, que não estão presentes nos documentos de arquivo. Estes documentos, portanto, não constituem mais, forçosamente, uma passagem obrigatória para a tomada de decisão, mas 
continuam essenciais, mormente em momentos de transição e rápidas alterações, pois lhes cabe atestar o funcionamento institucional, conferindo às instituições estabilidade graças ao autoconhecimento processual (Menne-Haritz, 2004).

Reitera-se assim, nesta visão macro dos arquivos e seus documentos, a importância da teoria arquivística ao enfatizar a interdependência dos documentos, produzidos no curso de processos que resultam em produtos (decisões, ações). Em outras palavras os documentos, na ótica arquivística, não são entendidos em sua autonomia, mas como partes de conjuntos maiores, conjuntos estes que lhes conferem sentido. Um documento isolado nada informa, na ótica arquivística, mas adquire sentido quando inserido no conjunto maior do qual faz parte, levando em conta as atribuições de quem o produziu ou recebeu. Documentos gerados no curso de processos administrativos geram documentos que atestam os produtos destes mesmos processos. A importância atribuída pela arquivologia ao conceito de "contexto" determina se não a maior diferença em relação a suas coirmãs (biblioteca e museu), certamente um traço distintivo essencial para ingressar na lógica arquivística.

Não me proponho aqui a resumir a teoria arquivística, mas é forçoso assinalar a especificidade do olhar lançado pela arquivologia em direção aos documentos pois os procedimentos de nomeação, organização e disseminação dos mesmos está subordinada a esta especificidade que, para simplificar, aqui foi denominada "contexto". É a partir do reconhecimento do contexto de produção e acumulação dos documentos arquivísticos que seu acesso pode ser implementado, contribuindo, de forma específica, para a realização do objetivo geral da área, a saber, "propor soluções práticas envolvidas no acesso à informação".

Processo e produto, passado e futuro, acervo e acesso, aparentemente constituem noções opostas, mas é na sua complementaridade que cada uma adquire sentido. Apesar das diferenças teóricas entre as 3 Marias, elas estão irmanadas no objetivo da CI: tal Jano e suas duas faces, elas identificam e preservam a ponte entre o passado e o futuro.

\section{Referências}

Bellotto, H.L. (1991). Arquivos permanentes: tratamento documental. São Paulo: T. A. Queiroz, 1991.

Briet, S. (1951). Qu'est-ce la documentation? Paris: Edit, 1951.
Buckland, M. (1991). Information as thing. // Journal of the American Society for Information Science 42: 5 (1991) 351-360.

Buckland, M. (1997). What is a "document"? // Journal of the American Society for Information Science 48: 9 (1997) 804-809.

Camargo, A.M.; Goulart, S. (2015). Centros de memória: uma proposta de definição. São Paulo: Edições Sesc São Paulo, 2015.

Homulos, P. (1990). Museums to libraries: a Family of collecting institutions. // Art Libraries Journal 15:1 (1990) 11-13.

Lund, N.W. (2009). Document theory. // Annual Review of Information Science and Technology 43 (2009) 399-432.

Menne-Haritz, A. (2004). Business processes: na archival Science approach to collaborative decision making, records, and knowledge management. Dordrecht: Kluwer Academic Publishers, 2004. (The Archivist's Libray, 3).

Otlet, P. (1934). Traité de documentation: le livre sur le livre. Bruxelas: Editiomes Mundaneum, 1934.

Smit, J.W. (2010). A interoperabilidade semântica entre os diferentes sistemas de informação no museu. // Seminário Serviços de Informação em Museus, I. São Paulo, 2010. (Publicado em 2011).

Smit, J.W. (1993). O documento audiovisual ou a proximidade entre as 3 Marias. // Revista Brasileira de Biblioteconomia e Documentação, 26:1/2 (1993) 81-85.

Copyright: (C) 2017. Smit. This is an open-access article distributed under the terms of the Creative Commons CC Attribution-ShareAlike (CC BY-SA), which permits use, distribution, and reproduction in any medium, under the identical terms, and provided the original author and source are credited. 